УДК 314. 15.015

$10.17213 / 2075-2067-2021-2-41-49$

\title{
ДЕМОГРАФИЧЕСКИЕ ЗНАНИЯ, ПРОФЕССИЯ ДЕМОГРАФ, ЭФФЕКТИВНОСТЬ ДЕМОГРАФИЧЕСКОЙ ПОЛИТИКИ
}

\author{
(C) 2021 г. О. Д. Воробьева ${ }^{* * * *}$, Т. В. Лебедева \\ "Институт демографических исследований \\ Федерального научно-исследовательского социологического центра РАН, \\ 2. Москва, Россия \\ ** Московский государственный университет \\ имени М. В. Ломоносова, г. Москва, Россия
}

Цель исследования. По результатам работы, проведенной 5-6 февраля 2021 года Третьей Воскресной зимней демографической школь (далее Школа) на базе Высшей школьы современных сочиальных наук (ВШССН) МГУ имени М. В. Ломоносова и Института демографических исследований Федерального научно-исследовательского сочиилогического иентра РАН (ИДИ ФНИСЦ РАН) РАН, и проведенного в ходе работы школь опроса слушателей оченить потребность в демографических знаниях у аудитории, разнообразной по своему профессиональному и образовательному составу.

Методологической основой исследования является обработка и анализ данных проведенного сочиологического опроса слушателей Школьл.

Результаты исследования. $B$ статье рассматриваются итоги проведенной Школьл. Анализ результатов проведённого опроса слушателей, которых благодаря возможности удалённого доступа подключения к работе Школь оказалось более 400 человек (в опросе приняли участие 200, обработаны 120 качественных анкет), продемонстрировал неожиданные результаты. Интерес к демографическим знаниям проявили не только студенты и аспиранты различных направлений подготовки, но и специалисты, преподаватели и научные работники. Прослеживается взаимосвязь между трудностями реализачии Начионального проекта «Демография» и отсутствием необходимых профессиональных знаний у непосредственных исполнителей проекта.

Ключевые слова: демографические проиессы; миграџионные проиессы населения; демографическая политика; демографическое образование.

\section{DEMOGRAPHIC KNOWLEDGE, PROFESSION DEMOGRAPHER, EFFECTIVENESS OF DEMOGRAPHIC POLICY}

\author{
(C) 2021 O. D. Vorob'yeva ${ }^{*, * *}$, T. V. Lebedeva ${ }^{* *}$
}

\section{"Institute of Demographic Research of the Federal Research Sociological Center of the Russian Academy of Sciences, Moscow, Russia **Lomonosov Moscow State University, Moscow, Russia}

Purpose of the study. According to the results of the work carried out on February 05-06, 2021, the Third Sunday Winter Demographic School (hereinafter referred to as the School) on the basis of the Higher School of Modern Social Sciences (HSSSN), Moscow State University named after 
M. V. Lomonosov and the Institute for Demographic Research of the Federal Research Sociological Center of the Russian Academy of Sciences (IDI FCISTS RAS) of the Russian Academy of Sciences and a survey of students conducted during the school's work, to assess the need for demographic knowledge among the audience, which is diverse in its professional and educational composition.

The methodological basis of the study is the processing and analysis of data from a sociological survey of students of the School.

Research results. The article discusses the results of the conducted School. The analysis of the results of the survey of students, who, thanks to the possibility of remote access to connect to the work of the School, turned out to be more than 400 people (200 took part in the survey, 120 high-quality questionnaires were processed) showed unexpected results. Interest in demographic knowledge was shown not only by students and graduate students of various fields of study, but also by specialists, teachers and researchers. There is traced the relationship between the difficulties of implementing the National Project "Demography» and the lack of the necessary professional knowledge of the direct executors of the project.

Key words: demographic processes; migration processes of the population; demographic policy; demographic education.

Введение. В сложившейся демографической ситуации в России, а также, судя по демографическим прогнозам, учитывая неблагоприятное развитие демографических процессов в перспективе, Правительство Российской Федерации разработало Национальный проект «Демография» [1], реализация которого началась со дня подписания Указа Президента Российской Федерации №204 от 7 мая 2018 года о 12 Национальных проектах.

По различным причинам поставленные в проекте задачи решаются не столь успешно, как это было намечено. По прошествии двух лет реализации появилось много вопросов. Почему, несмотря на огромные расходы федерального и региональных бюджетов, достичь поставленных целей не удается, намеченные показатели не достигаются, а продолжают падать [2, 3]? Суммарный коэффициент рождаемости, который в соответствии с Концепцией Демографической политики России должен был достичь величины 1,7 (число родившихся детей в год в среднем на одну женщину репродуктивного возраста), снижался и достиг к 2020 году 1,5 [4]! Средняя ожидаемая продолжительность предстоящей жизни при рождении (фактически показатель уровня смертности населения) не растет [5].

Среди множества причин социального, экономического, политического, даже чис- то демографического характера, есть одна, о которой пока не принято говорить, но уже очевидно, что ее влияние велико и эту причину нельзя сбрасывать со счетов. Это уровень профессиональных демографических знаний среди разработчиков и исполнителей государственных программ и проектов, ведь демографические процессы очень сложны. Поведение людей, особенно репродуктивное, самосохранительное, социальное, миграционное, зависит от очень многих обстоятельств. Оно имеет определенные, уже выявленные объективные закономерности в своем развитии, имеет сложные модели взаимозависимостей и взаимосвязей между собой $[6,7,8]$. Без знания этих закономерностей, без умения понять и проанализировать демографическую ситуацию, влияние причин и различного рода факторов, воздействующих на демографическое поведение людей, которое проявляется в виде определенных тенденций, невозможно влиять на него, воздействовать и эффективно управлять демографическими процессами (хотя понятие «управление» весьма условно относится к процессам регулирования демографических процессов).

Опыт проведения Третьей Воскресной зимней демографической школы в МГУ имени М.В. Ломоносова. Понимание того, 
что профессиональных знаний не хватает, чтобы справиться с кризисом в сфере демографических процессов, воспроизводства населения, миграционных процессов населения, все больше и больше появляется не только у управленцев, но и у студентов вузов.

Проиллюстрируем это на примере неожиданных (хотя вполне ожидаемых) результатов проведенной 5 и 6 февраля 2021 г. Третьей Воскресной зимней демографической школы на базе кафедры демографии факультета Высшей школы современных социальных наук (ВШССН) МГУ имени М.В. Ломоносова при поддержке Института демографических исследований Федерального научно-исследовательского социологического центра РАН (ИДИ ФНИСЦ РАН).

Зимняя школа проводилась уже в третий раз, но в этом году ее проведение состоялось в традиционном для последнего года удаленном, дистанционном формате. Вот тут и проявился огромный интерес к предлагаемой демографической тематике. В предыдущие годы участие в работе Школы могли принять немногие - из-за дорогих командировок, организации проживания присутствовать могли от 20 до 40 слушателей, преимущественно московского региона, доля приезжих из других регионов была ничтожно мала, хотя волею судеб оказывались на Школе и представители Алтая и других отдаленных регионов.

Но в этот раз такого препятствия, как расстояние, не было. Преодолели и барьер разницы во времени, организовав занятия только в первой половине дня, что позволило подключаться и сибирякам, и дальневосточникам, и желающим из стран ближнего зарубежья.

Количественный и качественный (в широком смысле слова) состав слушателей поразил. Откликнулись на приглашение принять участие в работе Школы - прослушать лекции, поучаствовать в дискуссии по заранее намеченной и разосланной в информационной письме программе - более двухсот

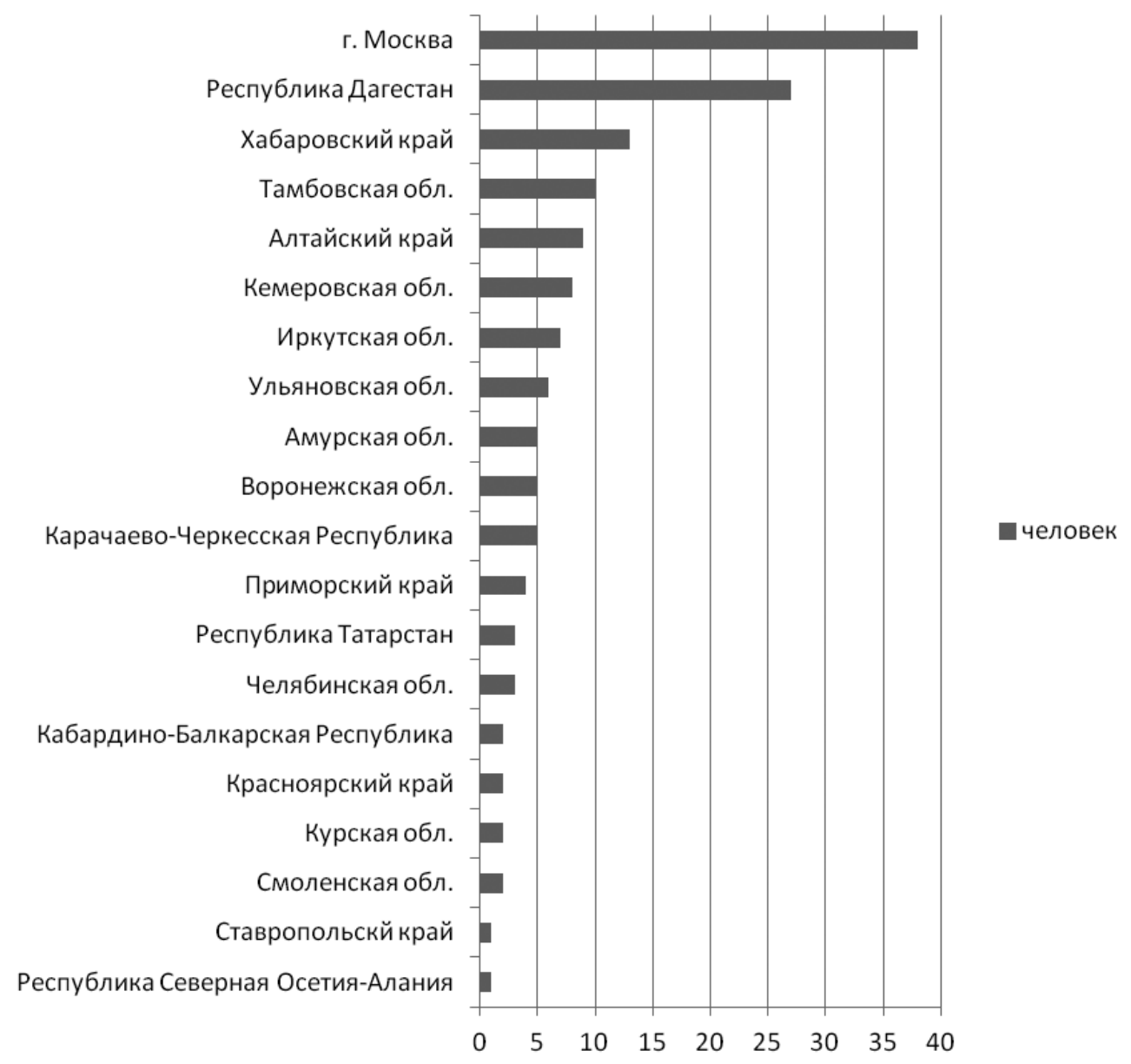

Рис. 1. Регионы проживания участников

Третьей Воскресной зимней демографической школы, человек 
студентов, преподавателей, специалистов разных профилей. Для данных слушателей небезразличны демографические проблемы России и своих стран, разнообразие и необходимость применения различных региональных подходов для их решения. Тематика слушателям Школы предлагалась достаточно узкая - двухдневная программа на тему «Миграция населения: спасение или угроза демографическому развитию России и ее регионов». В итоге разговор шел по гораздо более широкому кругу вопросов.
Приведем данные по региональному, профессиональному, образовательному и другим составам участников.

Из 209 слушателей Школы только 38 человек - представители Москвы, 27 человек подключились из Махачкалы (Республика Дагестан), 13 человек - из Хабаровска, 10 из Тамбова. Из 16 других субъектов Российской Федерации группы участников были менее 10 человек. Проранжировав регионы по числу слушателей Школы, получили следующую картину (рис. 1). О таком охвате, рассылая

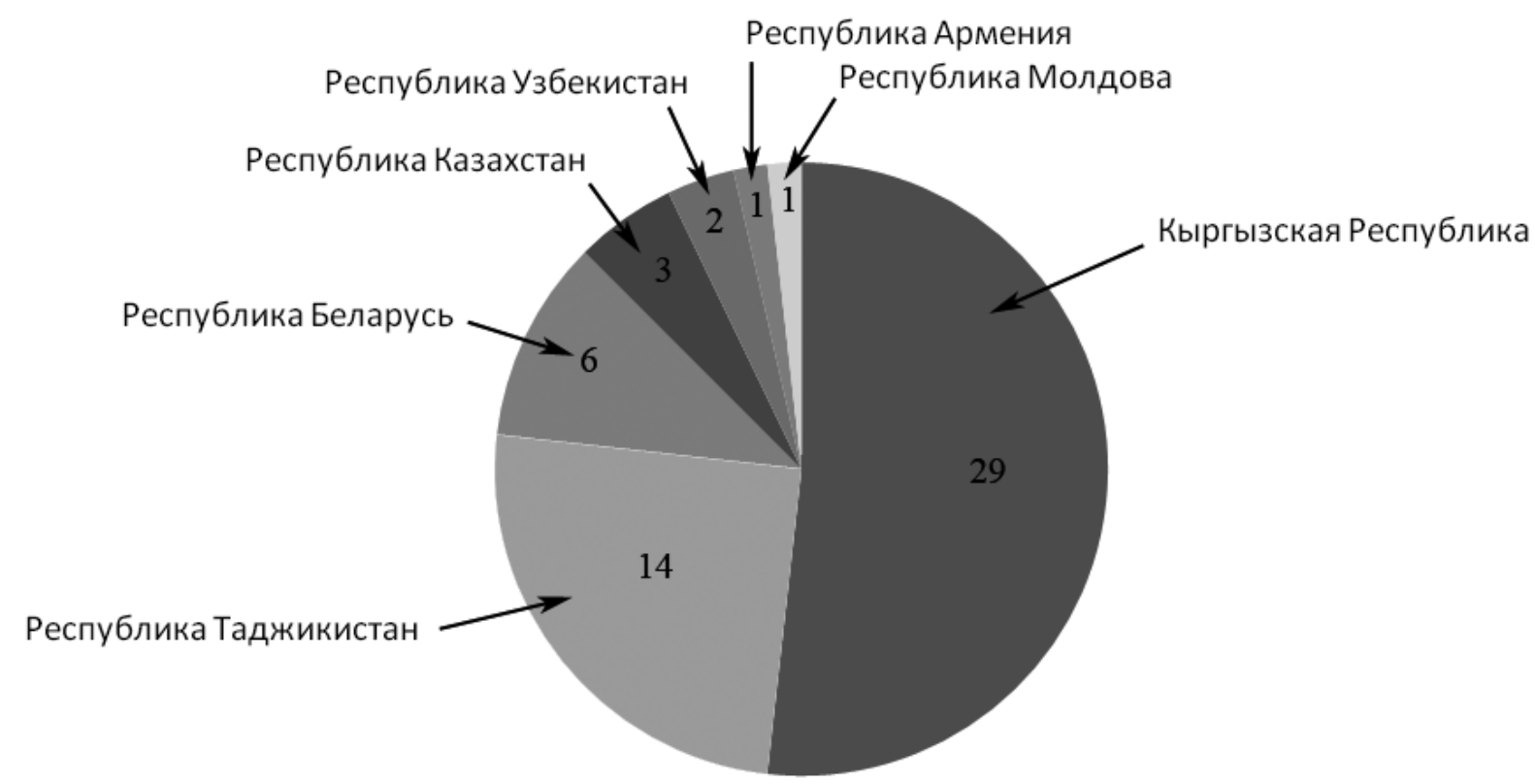

Рис. 2. Состав слушателей Третьей Воскресной зимней демографической школы из новых независимых государств, человек

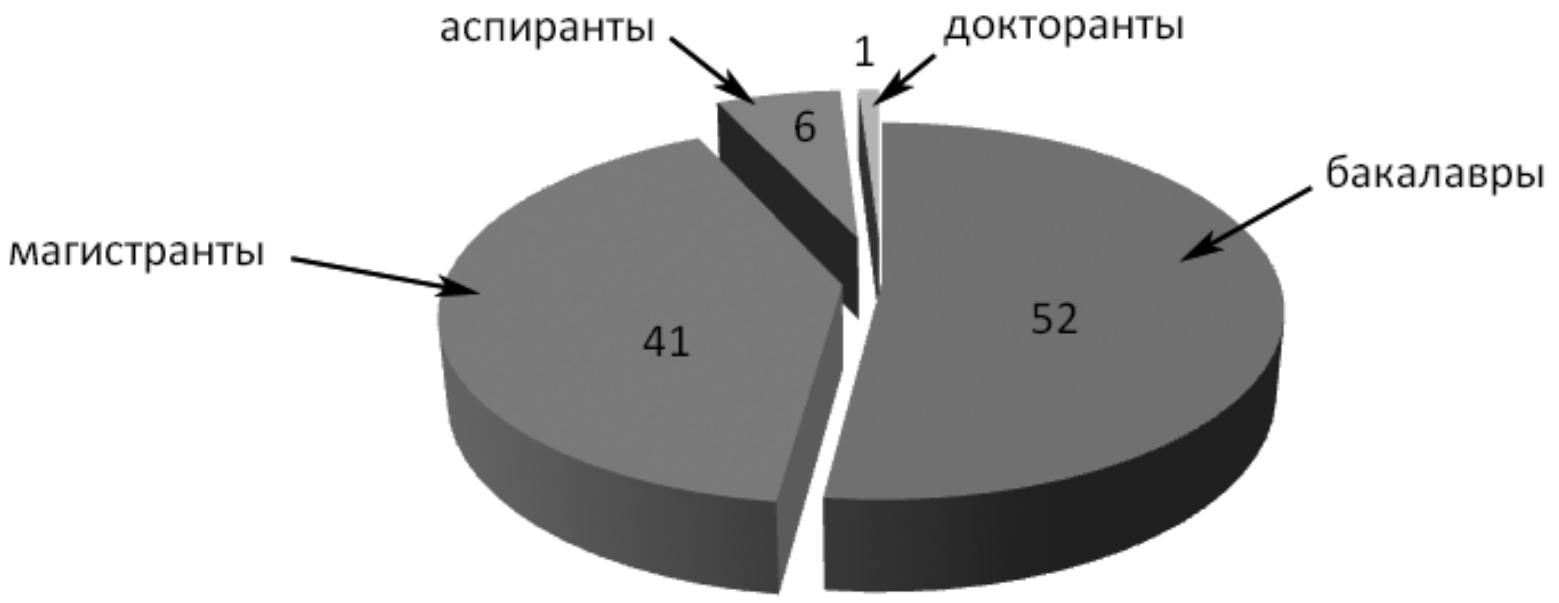

Рис. 3. Состав слушателей Третьей Воскресной зимней демографической школы, обучающихся по образовательным программам разного уровня, в \% 
информацию и приглашение принять участие в работе Школы, организаторы не мечтали даже приблизительно. Это ли не признак того, что демографические проблемы звучат в настоящее время очень тревожно, и есть острая потребность в расширении знаний о них?

Удивило и то, что практически четверть слушателей Третьей Воскресной зим- ней демографической школы (65 человек из 209) - это представители 7 новых независимых государств - Кыргызстана (Кыргызско-Российский Славянский университет им. Б.Н. Ельцина - 29 участников), Таджикистана (Институт экономики и демографии Национальной академии наук Республики Таджикистан - 14 участников), Беларуси,

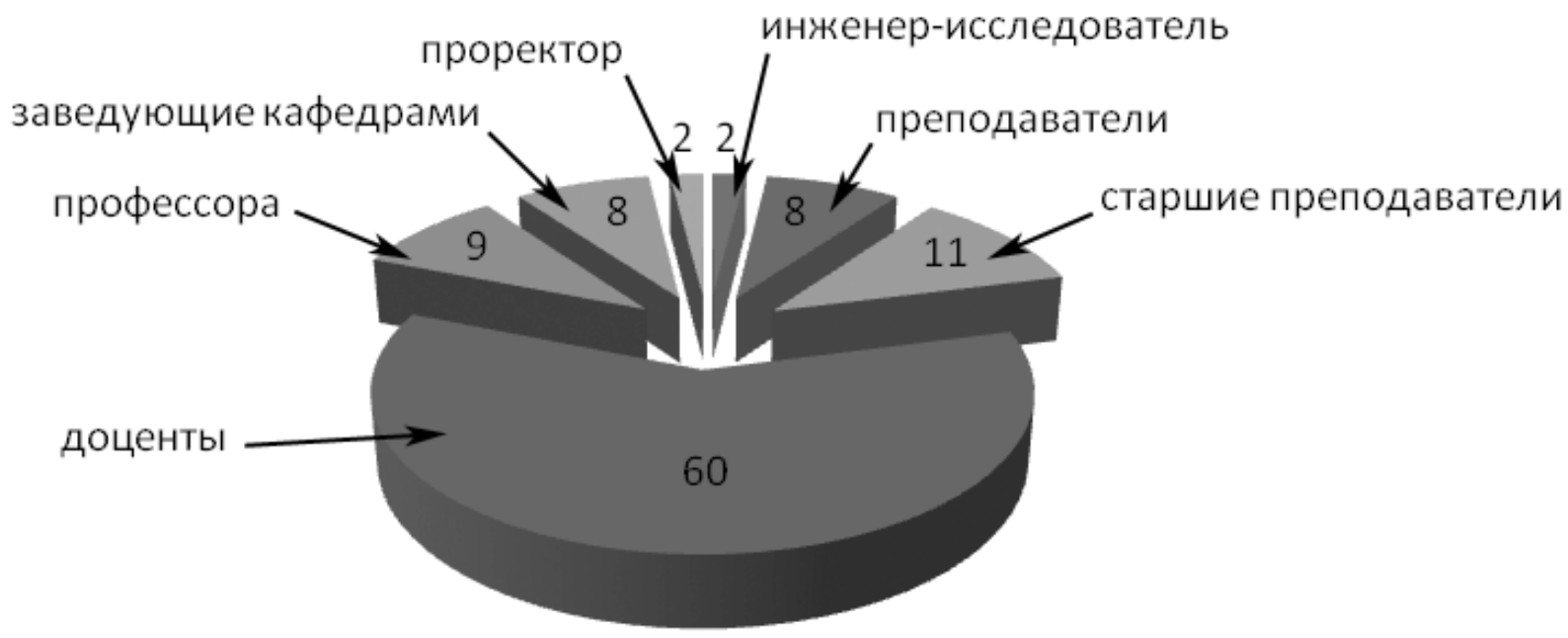

Рис. 4. Представители профессорско-преподавательского состава и научно-технические работники - слушатели Третьей Воскресной зимней демографической школы, в \%

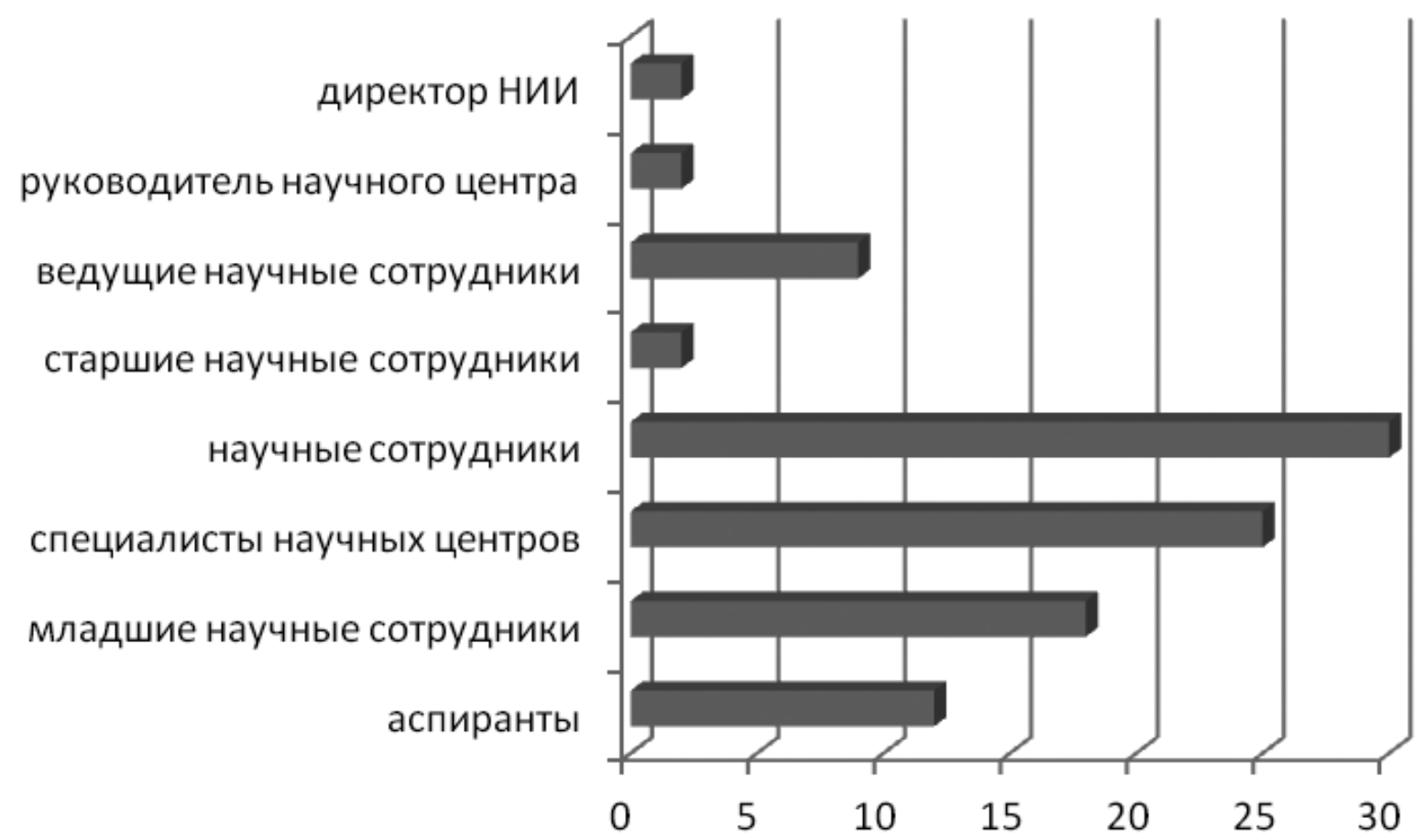

Рис. 5. Профессиональный состав представителей научных учреждений, участвовавших в работе Третьей Воскресной зимней демографической школы, в \% 
Казахстана, Узбекистана, Армении и Молдовы (рис. 2).

Наибольший интерес демографическая тематика вызвала у представителей вузовского сообщества. Практически половина слушателей (102 человека) — это студенты отечественных вузов и вузов государств-участников из ближнего зарубежья, обучающиеся по образовательным программам разного уровня, и 53 представителя профессорско-преподавательского состава и научно-технических работников (рис. 3,4$)$. Самой многочисленной группой из всего контингента участников Школы оказались студенты бакалавриата (53 человека или $25 \%$ всех участников Школы, и это $52 \%$ от всех слушателей, обучающихся в вузах). Вторую по численности группу среди слушателей Школы составили обучающиеся в магистратуре - 42 человека (20\% всех участников Школы, 41 \% от всех слушателей, обучающихся в вузах) (рис. 3).

Проявили интерес к работе Школы и 52 человека (или четверть от всех участников школы) из числа профессорско-преподавательского состава вузов. Среди них - 32 доцента (рис. 4).

В работе Школы также приняли участие 44 представителя научных учреждений - это практически каждый пятый участник Школы (21\%) (рис. 5). Евразийский Благотворительный фонд «Разбитые тела», а также глава и ведущий специалист Дипломатического
Представительства Агентства по внешней трудовой миграции при Министерстве занятости и трудовых отношений Республики Узбекистан в Российской Федерации, которым необходимы демографические знания в повседневной практической деятельности.

Для понимания эффекта от проведенных двух дней занятий, дискуссий, ответов на вопросы слушателям в заключительной части была предложена небольшая анкета из 5 вопросов, из которой явствует, что только 4 из 10 участников Школы изучали демографию в качестве учебной дисциплины в вузе. В анкете был вопрос «Будет ли Вам полезна полученная в ходе Третьей Воскресной зимней демографической школы демографическая информация?» с вариантами ответа, в какой именно сфере деятельности (для тех, кто ответил утвердительно). Ответивших утвердительно оказалось 97\% слушателей Школы, а уточнения о сфере деятельности выглядели следующим образом (рис. 6). В большей степени слушателей заинтересовали проблемы, связанные с миграцией населения: трудовая иммиграция и ее последствия (65\% ответов), эмиграция и потери человеческого капитала (56\%), проблемы получения достоверных данных по миграции (39\%), влияние миграции на быстрый рост или сокращение численности населения в разных регионах страны (34\%). Такое распределение ответов указывает, прежде всего, на представление

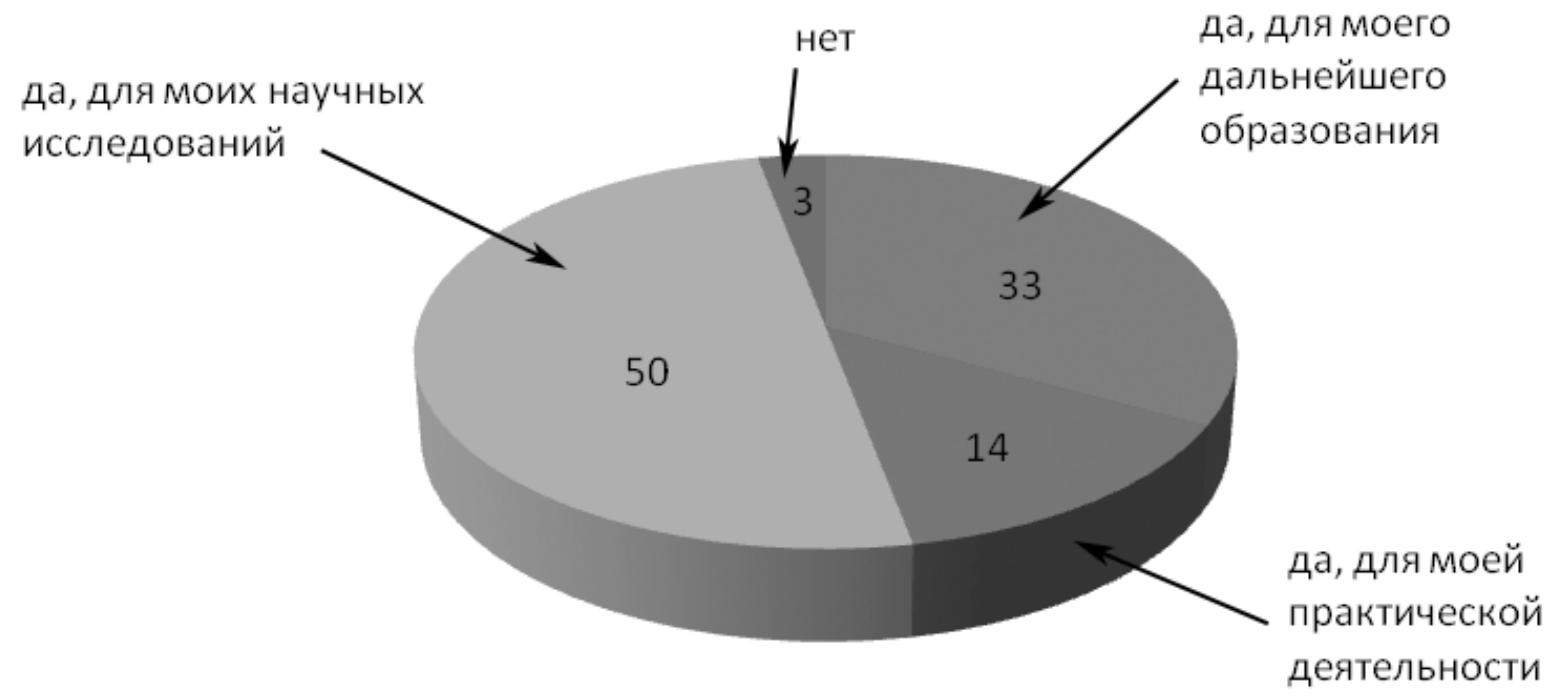

Рис. 6. Распределение ответов на вопрос о полезности полученной в ходе Третьей Воскресной зимней демографической школы демографической информации, в \% 
слушателей о самых серьезных вызовах в области миграции населения, которые стоят перед современным обществом.

Ответы на вопрос о потребности рассмотрения тематики на следующей демографической Школе показали, что наиболее интересными темами для обсуждения слушатели назвали опять-таки проблемы миграции населения (38\%), вызовы, связанные с демографическим старением населения (33\%) и современными тенденциями рождаемости $(21 \%)$.

Заключение. Востребованность в образовательном и профессиональном пространстве демографических знаний, благодаря возможности участия в Школе самых различных категорий населения, от студентов до преподавателей, практиков и научных работников, превзошла все ожидания. Стоит добавить, что в связи поздним поступлением заявок на участие в работе Школы (буквально накануне) не удалось подключить практически такое же, как и было подключено, число слушателей - еще более двухсот человек. Такая востребованность знаний в очень, казалось бы, узкопрофессиональной и специфической сфере деятельности должна найти отклик в форме разработки профессионального и образовательного стандарта для подготовки профессионалов-демографов, а это будет работать на эффективность проводимых в странах Евразийского пространства демографических политик самой разной направленности и национальных проектов в области демографического развития, какие бы цели ни стояли перед различными странами.

\section{Литература}

1. Национальный проект «Демография» [Электронный ресурс]. - Режим доступа: https://mintrud.gov.ru/ministry/programms/ demography (Дата обращения: 26.02.2021).

2. Обеспечение реализации национальных проектов на региональном уровне: Материалы семинара-совещания руководителей аналитических служб аппаратов законодательных (представительных) и исполнительных органов государственной власти субъектов Российской Федерации 2 апреля 2019 г. [Электронный ресурс] // Аналитический вестник. 一 №14 (728). — 95 с. - Режим доступа: http://council.gov.ru/media/files/eoqAP6 En2AenljBWVRsAny4HaBL7nqDT.pdf (Дата обращения: 20.02.2021).

3. Кондакова Н.А., Будилов А.П., Короленко A. $B$. Анализ реализации национального проекта «Демография» в России // Журнал исследований по управлению. - 2019. №5. - С. 48-55.

4. Послание Президента Российской Федерации Федеральному Собранию 15 января 2020 года [Электронный ресурс]. — Peжим доступа: http://www.kremlin.ru/events/ president/news/62582 (Дата обращения: 25.02.2021).

5. Ожидаемая продолжительность здоровой жизни в России: региональные особенности и прогнозы. Заседание Демографической секции Центрального дома ученых РАН [Электронный pecypc] // ДемоскопWeekly. 26 марта - 8 апреля 2018 г. — №765-766. Режим доступа: http://www.demoscope.ru/ weekly/2018/0765/nauka01.php (Дата обращения: 28.02.2021).

6. Практическая демография: пособие для руководителей и специалистов органов государственного управления / Под ред. С. В. Рязанцева, О.Е. Лисейчикова. - Минск: Альтиора-Форте, 2017. - 194 с.

7. Статистика населения и демография: Учебник + Приложение. Тесты / О.Д. Воробьева, Т.А. Долбик-Воробей. - М.: КНОРУC, 2019. - $314 \mathrm{c}$.

8. Экономика народонаселения: Учебник / Под ред. проф. В.А. Ионцева (Учебники экономического факультета МГУ имени М.В. Ломоносова). - М.: ИНФРА-М, 2007. -668 c.

\section{References}

1. Nacional'nyj proekt «Demografija» [National project «Demography»] [Jelektronnyj resurs]. — URL: https://mintrud.gov.ru/ministry/programms/demography (Date accessed: 26.02.2021).

2. Obespechenie realizacii nacional'nyh proektov na regional'nom urovne: Materialy seminara-soveshhanija rukovoditelej analiticheskih sluzhb apparatov zakonodatel'nyh (predstavitel'nyh) i ispolnitel'nyh organov gosudarstvennoj vlasti subektov Rossijskoj Feder- 
acii 2 aprelja 2019 g. [Ensuring the implementation of national projects at the regional level: Materials of the seminar-meeting of heads of analytical services of the offices of legislative (representative) and executive bodies of state power of the subjects of the Russian Federation on April 2, 2019] [Jelektronnyj resurs] // Analiticheskij vestnik [Analytical Bulletin]. — №14(728). 95 s. - URL: http://council.gov.ru/media/files/ eoqAP6En2AenIjBWVRsAny4HaBL 7nqDT. pdf (Date accessed: 20.02.2021).

3. Kondakova N.A., Budilov A.P., Korolenko $A . V$. Analiz realizacii nacional'nogo proekta «Demografija» v Rossii [Analysis of the implementation of the national project «Demography» in Russia] // Zhurnal issledovanij po upravleniju [Journal of Management Studies]. 2019. — №5. - Pp. 48-55.

4. Poslanie Prezidenta Rossijskoj Federacii Federal'nomu Sobraniju 15 janvarja 2020 goda [Message of the President of the Russian Federation to the Federal Assembly on January 15, 2020] [Jelektronnyj resurs]. — URL: http:// www.kremlin.ru/events/president/news/62582 (Date accessed: 25.02.2021).

5. Ozhidaemaja prodolzhitel'nost' zdorovoj zhizni v Rossii: regional'nye osobennosti i prognozy. Zasedanie Demograficheskoj sekcii
Central'nogo doma uchenyh RAN [Healthy life expectancy in Russia: regional features and forecasts. Meeting of the Demographic Section of the Central House of Scientists of the Russian Academy of Sciences] [Jelektronnyj resurs] // DemoskopWeekly. 26 marta -8 aprelja 2018 g. №765-766. — URL: http://www.demoscope.ru/ weekly/2018/0765/nauka01.php (Date accessed: 28.02.2021).

6. Prakticheskaja demografija: posobie dlja rukovoditelej i specialistov organov gosudarstvennogo upravlenija [Practical demography: manual for managers and specialists of public administration bodies] / In S. V. Rjazancev, O.E. Lisejchikov (eds.). - Minsk: Al'tioraForte, 2017. - 194 p.

7. Statistika naselenija i demografija: Uchebnik + Prilozhenie. Testy [Population statistics and demography: Textbook + App. Tests] / O.D. Vorob'eva, T.A. Dolbik-Vorobej. - Moscow: KNORUS, 2019. - 314 p.

8. Jekonomika narodonaselenija: Uchebnik [Population Economics: Textbook] / In prof. V.A. Ioncev (eds.) (Uchebniki jekonomicheskogo fakul'teta MGU imeni M.V. Lomonosova [Textbooks of the Faculty of Economics of the Lomonosov Moscow State University]). Moscow: INFRA-M, 2007. - 668 p. 

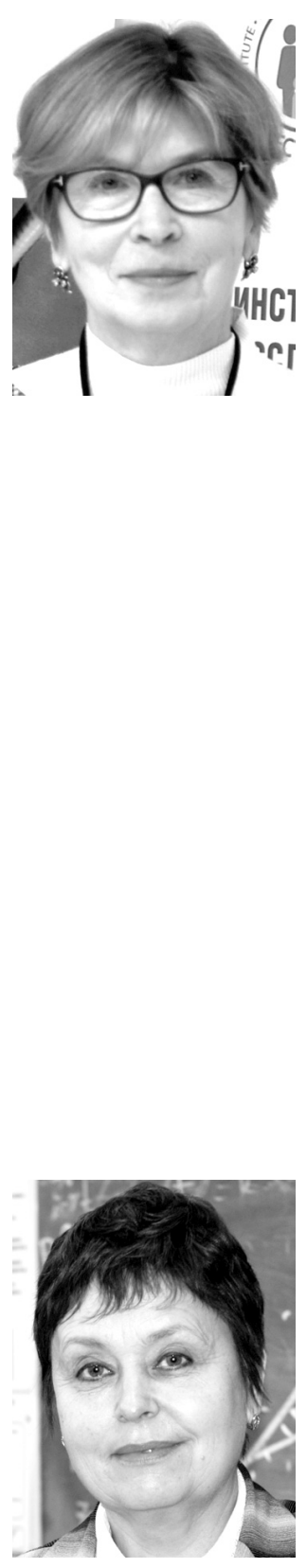

Воробьева Ольга Дмитриевна - доктор экономических наук, профессор, главный научный сотрудник Института демографических исследований ФНИСЦ РАН, профессор кафедры демографии Высшей школы современных социальных наук (факультет) МГУ имени М.В. Ломоносова.

Vorob'yeva Olga Dmitrievna - Doctor of Economic Sciences, Professor, Chief Researcher, Institute of Demographic Research of the Federal Research Center of the Russian Academy of Sciences (IDR FCISTS RAS); Professor of the Department of Demography of the Higher School of Modern Social Sciences (faculty), Lomonosov Moscow State University.

119333, г. Москва, ул. Фотиевой, 6, корп. 1

6 Fotievoy st., bld. 1, 119333, Moscow, Russia

E-mail: 89166130069@mail.ru

119992, г. Москва, Ленинские горы, 1, корп. 13А

1 Leninskie gory, bld. 13A, 119992, Moscow, Russia

E-mail: 89166130069@mail.ru

Лебедева Тамара Васильевна - кандидат географических наук, доцент, научный сотрудник кафедры демографии Высшей школы современных социальных наук (факультет) МГУ имени М.В. Ломоносова.

Lebedeva Tamara Vasilievna - Candidate of Geographical Sciences, Associate Professor, Researcher, Department of Demography, Higher School of Modern Social Sciences (Faculty), Lomonosov Moscow State University.

119992, г. Москва, Ленинские горы, 1, корп. 13А 1 Leninskie gory, bld. 13A, 119992, Moscow, Russia E-mail: shonohova@rambler.ru 